\title{
EL ESCARABEO EGIPTIZANTE DE LA ALCUDIA (ELCHE, ALICANTE)
}

\author{
MARINA ESCOLANO POVEDA*
}

\begin{abstract}
Resumen. En este artículo se realiza un estudio del escarabeo de La Alcudia (Elche, Alicante) con el objetivo de aportar una interpretación del entalle de su base que lo acerque a modelos mediterráneos y clarificar su origen y datación.

Palabras clave: Escarabeo, Alcudia, Egiptizante, Ptah
\end{abstract}

\begin{abstract}
This article makes a study of the scarabaeus of La Alcudia (Elche, Alicante), in order to give an interpretation of the engraving of its base that brings it nearer to the Mediterranean models, and to clarify its origin and date.

Key words: Scarab, Alcudia, Egyptianising, Ptah
\end{abstract}

\section{INTRODUCCIÓN}

Los escarabeos son algunas de las piezas de tipología egipcia que con mayor frecuencia aparecen en los niveles fenicio-púnicos de los yacimientos del área mediterránea de la Península Ibérica, aunque también están presentes en niveles ibéricos y romanos. Se trata de piezas que han ejercido a lo largo de la historia un gran poder de atracción sobre la gente debido a su sutil belleza, a la atribución a los mismos de propiedades "mágicas", o simplemente a su carácter de objetos exóticos, lo cual llevó a su exportación desde su tierra de origen, Egipto, y a su dispersión, de la mano de los fenicios y posteriormente de los cartagineses, por todo el Mediterráneo. La gran demanda que había de escarabeos llevó a la fabricación de copias en talleres fuera de Egipto, e incluso al grabado de motivos helenizantes en lugar de egipcios.

\footnotetext{
* Agradecemos al Dr. José Miguel Serrano Delgado, a la Dra. M ${ }^{a}$ José López Grande y a Francisco L. Borrego Gallardo su revisión del artículo, y a la Dra. Pilar González-Conde Puente la coordinación del mismo. Además, queremos reconocer la ayuda del Dr. Alfredo González Prats al proporcionarnos bibliografía específica, así como al Dr. Erhart Graefe por facilitar la utilización de la biblioteca del Institut für Ägyptologie und Koptologie de Münster. Por último, damos las gracias a la Fundación Universitaria de Investigación Arqueológica La Alcudia por permitirnos el acceso a la pieza.
}

Pese a que el tema ha sido ampliamente tratado por la historiografía ${ }^{1}$, haremos unos breves apuntes sobre el significado del escarabeo en el Egipto antiguo, por situarse en él su origen. El escarabeo es una representación del escarabajo pelotero (Scarabaeus sacer), muy abundante en Egipto en la Antigüedad, aunque Petrie reconoce en su clasificación cuatro especies más de escarabajos en las representaciones de los escarabeos, el catharsius, el copris, el gymnopleurus y el hypselogenia (Petrie, 1917). Este coleóptero fue venerado en el Egipto antiguo desde tiempos prehistóricos, muestra de lo cual son los ejemplares que se han conservado, guardados en tinajas, o las representaciones en alabastro de estos escarabajos, los primeros escarabeos ${ }^{2}$ (Petrie, 1917, 2). El escarabajo era considerado en el Egipto antiguo como una manifestación del dios Khepri, dios creador vinculado al Ciclo del Sol, como el Sol del Amanecer, y que era representado como un dios antropomorfo con un escarabajo en lu-

1. Véanse al respecto los capítulos introductorios de las obras de Newberry (1905) y Petrie (1917), así como el capítulo "De bestia a dios: el escarabajo sagrado" de la obra clásica de Lange (1961).

2. Los escarabeos en los que figuran nombres de faraones anteriores a la XII dinastía se han atribuido la Baja Época en muchos casos. Para las primeras dinastías era más común el uso de cilindros giratorios a modo de sellos que el de escarabeos. Newberry $(1905,66)$ afirma que los escarabeos no fueron utilizados hasta el final de la VI dinastía. 
gar de cabeza, como se puede ver en la representación del mismo a la izquierda de la puerta que da acceso a la cámara lateral en la tumba de la reina Nefertari. Esta asociación se debía a la observación del comportamiento de este animal, que fabricaba con estiércol una gran bola (del tamaño de una pelota de tenis) donde desovaba. La imagen del escarabajo haciendo rodar la bola con sus patas, y la posterior ocultación de la misma bajo tierra, inspiró a los egipcios la imagen del dios Khepri empujando al Sol a través del firmamento, y haciendo que se ocultara bajo el horizonte. Asimismo, la visión de las larvas naciendo del interior de la bola de estiércol hizo creer a los antiguos egipcios que sólo existían escarabajos machos, por lo que el dios Khepri se identificó como el "Padre de los Dioses", relacionándolo con Ra-Atum, creador de la Enéada heliopolitana. La aparición de las larvas de escarabajo del interior de la tierra les hizo creer que por este proceso el primer escarabajo se regeneraba a sí mismo. Esto explica también el hecho de que el escarabajo, cuyo nombre es grafía del verbo egipcio 雀 $h p r$, cuyo significado es "llegar a ser", "transformarse", "convertirse en" (Faulkner, 1988).

El escarabeo en el Egipto antiguo tenía distintas funciones, entre las que estaban la de sello, considerada principal por Newberry, amuleto, medalla, joya o elemento de valor empleado en los trueques (Newberry, 1905), y que podían ser aportadas por la inscripción grabada en su base, en caso de que la tuviera. En la Península Ibérica, en cambio, hemos de considerar los escarabeos desde otro punto de vista, ya que estos objetos no formaban parte, como ocurría para los egipcios, de la religiosidad popular. Fuera de Egipto estos objetos serían vistos como amuletos mágicos, pero no por su relación con el dios egipcio Khepri, sino por su origen exótico y su carácter oscuro, debido en parte a los jeroglíficos y representaciones de su base, consideradas como fórmulas mágicas, aunque no pudiesen ser comprendidas por sus poseedores. Otra función de los escarabeos fuera de Egipto sería la de objetos de prestigio, como ocurre con las otras importaciones orientales, debido a su carácter de productos de lujo, por lo que serían utilizados como joyas, sobre todo aquellos engastados en monturas de metales preciosos (Feghali, 1996).

\section{EL ESCARABEO DE LA ALCUDIA (ELCHE)}

En una de las vitrinas del Museo de La Alcudia (Elche), situado entre otras piezas orientalizan- tes se encuentra un pequeño escarabeo procedente de las excavaciones del yacimiento.

\section{II.1. Historiografía}

Existen referencias bibliográficas al escarabeo de La Alcudia en diversas publicaciones, aunque nunca, hasta ahora, ha sido objeto de un estudio detallado. La primera mención que encontramos la hace A. Ramos Folqués, refiriéndose a él como Un escarabeo de pasta imitando el diapro verde, de estilo egipcio, con entalle en su base representando una figura sentada en el suelo con las piernas cruzadas y con una tabla sobre ellas, como escribiendo (Ramos Folqués, 1950, 205). En este artículo, Ramos Folqués clasifica el escarabeo junto con otra serie de objetos orientalizantes aparecidos en el yacimiento ilicitano, que según él habrían sido traídos por los cartagineses. Cinco años después, el mismo autor publicó otro artículo con una nueva referencia al escarabeo en la que no menciona el material de que está hecho: También procede de La Alcudia un escarabeo de color verde, con entalle en su base representando una figura sentada en el suelo con las piernas cruzadas y con una tabla sobre ellas. (Ramos Folqués, 1955, 306). En esta publicación, Ramos Folqués adjunta un dibujo, muy esquemático, del mismo. R. Ramos Fernández, en 1974, publica una fotografía de la parte inferior del escarabeo, pero no alude a él en el texto (Ramos Fernández, 1974, 60).

Pese a que no se indica en ningún lugar el espacio donde apareció el escarabeo ni el año en que fue hallado, las siguientes palabras de A. Ramos Folqués nos hacen pensar que fue él su descubridor: [...]en las excavaciones que realizo en este yacimiento arqueológico, y siempre en los estratos inferiores del mismo, he encontrado algunos restos de carácter cartaginés, que por analogía con otros de su especie tienen una cronología que coincide con la por mí asignada a los estratos en que han aparecido y que abarca el periodo del siglo IV al II antes de J. C.. (Ramos Folqués, 1955, 303). Encontramos también una primera datación en base a la estratigrafía del yacimiento según Ramos Folqués.

En 1978, I. Gamer-Wallert, en su recopilación de los hallazgos egipcios y egiptizantes de la Península Ibérica, dedica un apartado a Elche, donde hace una breve referencia al escarabeo: [...] wird auch der Skarabäus aus grünschwarzem Stein, der gegen Ende des 3. bis Anfang des 2. Jahrhunderts v. Chr. auf die Alcudia ge- 
langt sein mag, eine außerägyptische Imitation darstellen." (Gamer-Wallert, 1978, 183). GamerWallert identifica el material del escarabeo como piedra de un color verde-negro, y acota la datación con respecto a Ramos Folqués. Asimismo, considera el escarabeo como una imitación de procedencia no egipcia, y lo relaciona con el escarabeo de El Castellar Colorat, de Crevillente, anepígrafo.

La última referencia que hemos encontrado a esta pieza aparece en la recopilación de objetos de tipo egipcio hecha por J. Padró i Parcerisa y publicada en dos volúmenes en 1980 y 1983. En el segundo de éstos dedica un apartado a La Alcudia, dentro del cual hace un subapartado para el escarabeo (Padró, 1983, 120), donde lo describe como un escarabeo de jaspe verde (diaspro), de 1,1 cm de largo, 0,9 cm de ancho y $0,7 \mathrm{~cm}$ de altura. Menciona, además, que fue encontrado en el nivel llamado ibero-púnico por Ramos Folqués. En cuanto a su datación, Padró se abstiene de realizarla a partir del contexto arqueológico, argumentando lo impreciso de dichos datos, o desde criterios estilísticos, por no haberle sido posible examinar la pieza directamente, aunque considera que su aspecto no es egipcio y le atribuye una fecha del s. IV a. C. En cuanto a la descripción que hace de la pieza, se basa en las fotografías, dibujos y comentarios de Ramos Folqués, que debido a su calidad no le permiten hacer un estudio detallado ni establecer paralelos, al no poder identificar el grabado de la base. Finalmente concluye que se trata de un escarabeo de manufactura occidental, apuntando Cerdeña como posible origen. Padró ofrece al final de su libro tres imágenes del escarabeo (Padró, 1983, Lám. LIX, 17.01).

\section{II.2. Descripción}

El escarabeo de La Alcudia está fabricado en jaspe verde, y mide 1,1 cm de largo, 0,9 cm de ancho, y 0,7 cm de alto, como ya indicaba J. Padró en su recopilación de objetos de tipo egipcio de la Península Ibérica (Padró, 1983, 120). Posee una perforación longitudinal de sección circular y un esquema dorsal que puede clasificarse como una variante del tipo II de Vercoutter, es decir, con protórax indicado pero con élitros también indicados. Tiene las patas indicadas de forma esquemática, y presenta un entalle en su reverso. La técnica con la que ha sido elaborado es bastante simple con respecto a la de los escarabeos de jade encontrados en Ibiza (Fernández y Padró, 1982).

\section{II.2.1. La inscripción}

El aspecto más llamativo de este pequeño escarabeo es el entalle de su base. En él, rodeada de una orla pseudosogueada, encontramos una figura sentada. Como hemos visto, ésta fue interpretada por Ramos Folqués (Ramos Folqués, 1950 y 1955) como la figura de un escriba sentado con las piernas cruzadas y con una tabla sobre ellas, en actitud de escribir. No obstante, pese a que esta representación existe en el arte egipcio desde el Reino Antiguo, como podemos ver en los exquisitos relieves de la mastaba de Mereruka en Saqqara, era más común la alusión a este oficio mediante el jeroglífico con el que se

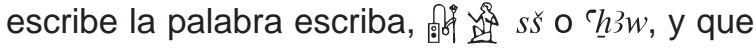
representa sus instrumentos de trabajo, la paleta con la tinta roja y negra, el pincel y el recipiente para el agua.

La figura grabada en la base del escarabeo posee una serie de atributos que nos permiten identificarla con el dios Ptah, 8 pth, el dios menfita patrón de los artesanos, también considerado un dios creador por su relación con la artesanía. La postura en que aparece es la utilizada para representar las figuras humanas en los jeroglíficos determinativos, como una figura sentada de perfil con las piernas flexionadas y recogidas hacia el cuerpo (路 A40 de Gardiner). No presenta ningún objeto ni símbolo sobre la cabeza, pero podemos apreciar en la mitad derecha de la misma una línea vertical, que se une a una línea horizontal que la divide, y que pudieran indicar la existencia de un bonete cubriéndola. En la parte inferior de la cabeza podemos observar una protuberancia de forma rectangular, que representa la barba recta del dios. Ptah es el único dios egipcio que lleva barba recta, en lugar de la barba curva del resto de dioses.

Sobre la frente de la figura vemos una línea que podría indicar la existencia de un úreo (的 164 de Gardiner). Este símbolo aparece en algunas representaciones de Ptah como artesano, sentado frente al torno dando forma al huevo primordial (Castel, 2001, 339). Ptah fue pronto asimilado a Tatjenen, dios ctónico, dando lugar a Ptah-Tatjenen, como dios creador; así como a Sokar, divinidad de la necrópolis de Menfis, tomando la forma de Ptah-Sokar-Osiris. Ptah asume por estas asociaciones aspectos de estos dioses en su faceta de dios creador y funerario, así como algunos de sus atributos, como podemos ver en la pared este de la antecámara de la tumba de Amenherkhepshef (QV 55), hijo de Ramsés III, en el Valle de las Reinas, donde aparece el dios con sus atributos habituales, y el úreo 


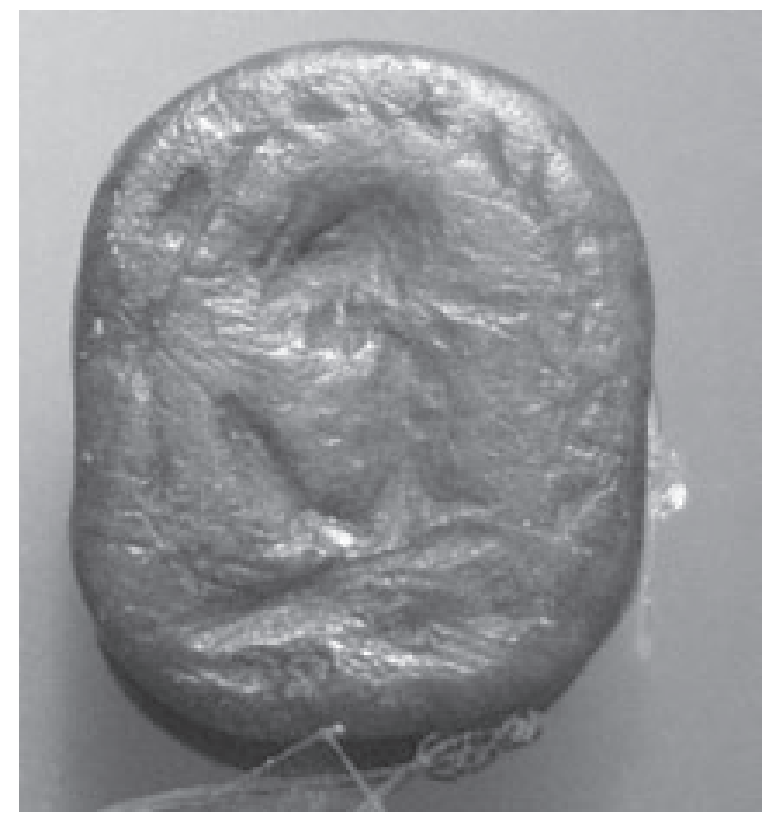

Figura 1: Entalle del escarabeo de La Alcudia.

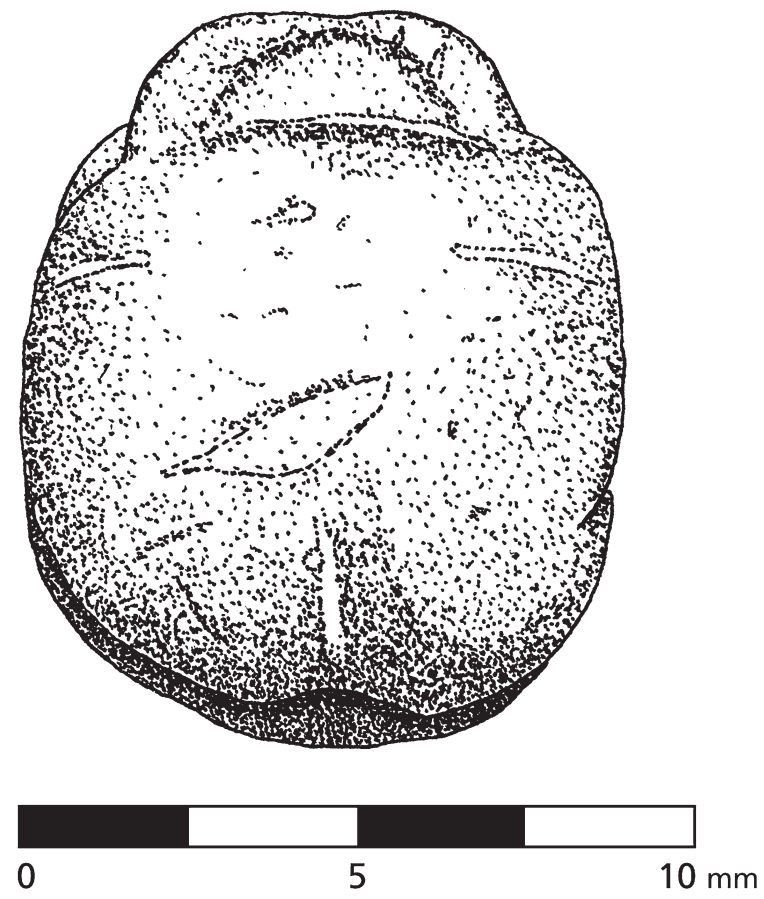

Figura 3: Vista dorsal del escarabeo de La Alcudia.

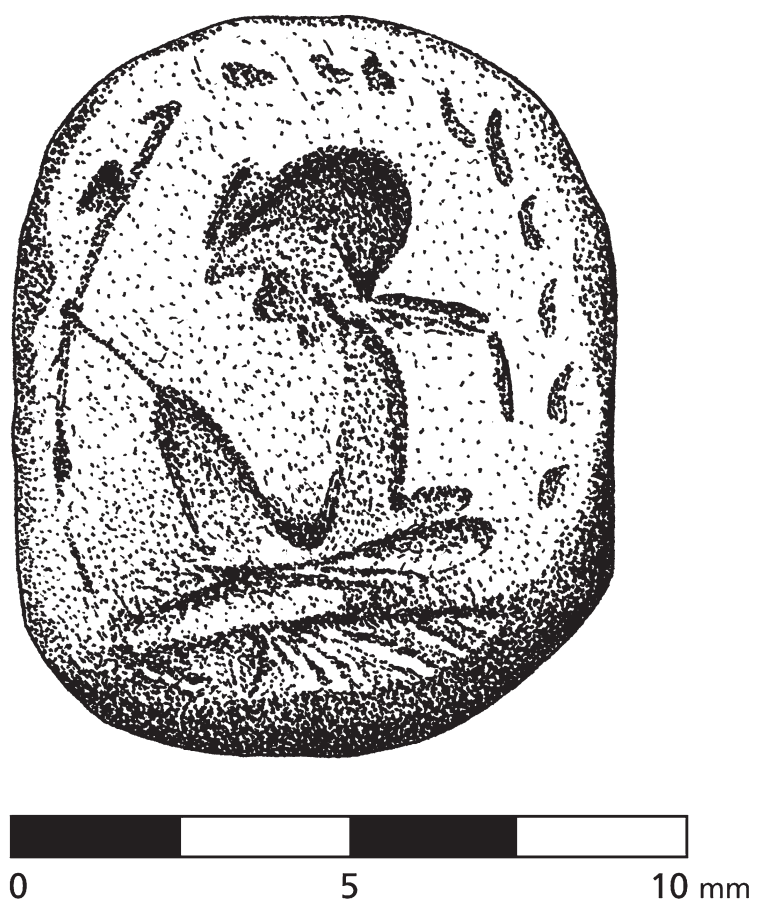

Figura 2: Entalle del escarabeo de La Alcudia.

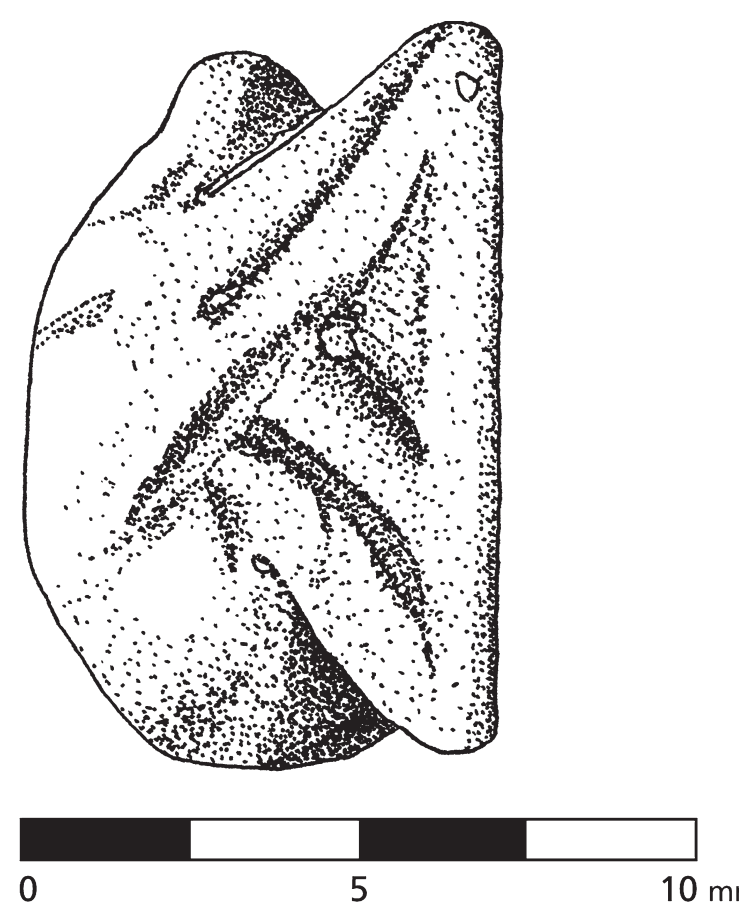

Figura 4: Vista lateral del escarabeo de La Alcudia. 
sobre la frente, siendo denominado en el texto jeroglífico como el que está al frente de Tatjenen", cuyo significado es "La tierra emergida", es decir, el montículo primigenio ${ }^{3}$. Hacia la derecha en la misma pared vemos una representación de Ptah-Tatjenen portando asimismo el úreus.

De la parte posterior de su cuello sale una línea que desciende en una curva, detalle también presente en los escarabeos de Ptah clasificados por Vercoutter (Vercoutter, 1945) con los números 58, 73, 209, 262, 378 y en el escaraboide 431. En el catálogo de Newberry (Newberry, 1905) este detalle está indicado en el escarabeo 42 de la lámina XXIX, en los escarabeos 2 y 9 de la lámina XXXVI y en el 13 de la lámina XLI. Se trata del contrapeso del collar usekh (C) S11 de Gardiner), collar de oro con propiedades protectoras, llamado en ocasiones "guirnalda de Atum" por tener nueve filas, que se vinculan a la Enéada heliopolitana, e incluso "guirnalda de Khepri" (Castel, 1999).

Otro atributo de este dios que encontramos en el escarabeo es el cetro uas (? S40 de Gardiner) que sale de la zona de las rodillas del dios, zona donde se suelen situar los atributos de mano de los dioses en las representaciones sedentes de los mismos. Encontramos esta misma representación en el escarabeo 64 y los escaraboides 431, 432 y 471 de Vercoutter, y en el 2 de la lámina XXXVI de Newberry.

Pese a que no tiene un trazo preciso, parece distinguirse bajo la figura el signo del cesto ( $\smile$ V30 de Gardiner) con el interior rayado expresamente, presente también en la parte inferior de los escarabeos en los que aparece representado el dios Ptah 64, 209, 262 y 378, y en el escaraboide con este mismo dios 431 de Vercoutter. Este signo suele ir acompañado también de $h s$, "alabanza", significando el conjunto de los tres signos ptḥ $n b$ h $s(w t)$, "Ptah, señor de las alabanzas". No obstante, encontramos los dos signos juntos representados en el escaraboide 431 de Vercoutter. La aparición de este signo, sin un significado especial, es común en los escarabeos de jaspe de manufactura occidental, en los que actúa a modo de base para las figuras situadas sobre él, frecuentemente rayado o reticulado, como indica Acquaro: In basso, un nb a reticolato rettifica con un piano d'appoggio ori-

3. Otra interpretación sobre esta inscripción aportada por Elisa Castel es que se trate de una fusión de los dioses Ptah, Khenty y Tatjenen. zzontale l'ovale del campo figurativo (Acquaro, 1984, 82).

\section{CONCLUSIÓN}

El escarabeo de La Alcudia presenta un estilo similar al encontrado en Ibiza y numerado como el 24 del catálogo de Padró y Fernández (1982), ya que en ambos la representación grabada en la base del mismo está rodeada por una orla pseudosogueada realizada a base de pequeños trazos inclinados. La calidad del entalle es, además, similar. Este escarabeo, no obstante, aparece catalogado sin datación, con lo que no sirve de ayuda para fechar el de La Alcudia. Este tipo de orla pseudosogueada la encontramos también en un escarabeo de jaspe verde de la Collezione Biggio de Sant' Antíoco, Cerdeña, para el que Acquaro propone una datación de principios del s. V a. C. (Acquaro, 1984, figs. 102 y 103).

En lo que se refiere a la iconografía, la figura representada en el entalle parece ser el dios egipcio Ptah, cuyo culto se difundió por el Mediterráneo en época tardía, principalmente en la forma del culto a sus hijos como dios de la artesanía, los patecos, cuyas imágenes, según Heródoto (III, 37), eran colocadas por los fenicios en la proa de sus trirremes como protección. Estos amuletos tenían forma de enanos representados de frente con las manos en las caderas, la cabeza calva o con pelo corto, o cabeza de halcón o carnero, con la trenza lateral, un escarabajo o la corona atef sobre ella (Wilkinson, 2003). En La Alcudia se ha encontrado un supuesto pateco fabricado en coral, actualmente conservado en el museo del yacimiento. Esta identificación, no obstante, no es clara.

No hemos hallado ningún paralelo de esta imagen en escarabeos de jaspe verde. En el catálogo de Vercoutter los escaraboides 431 y 432 , fechados en los siglos VII y VI a. C., y el escarabeo 64, de principios del S. VII a. C., presentan una imagen de Ptah igual a la del escarabeo de La Alcudia, estando los dos primeros fabricados en pasta coloreada, y el tercero en pasta friable. Estos escaraboides y escarabeo de pasta, según Vercoutter, serían de procedencia egipcia. Según este mismo autor, los escarabeos representando a Sekhmet y a Ptah no se encuentran jamás en Náucratis, lugar de fabricación principal de los escarabeos egipcios hallados en el Mediterráneo, con lo que un posible origen de los mismos sería Menfis (Vercoutter, 1945, 340 y 341), capital de Egipto desde que fuese trasladada desde Tebas por Psamético I (664-610). No obstante, cabe 
destacar que no hemos encontrado ningún paralelo de esta imagen de Ptah en suelo egipcio.

Los escarabeos de jaspe verde, como el de La Alcudia, reemplazan, según Vercoutter (Vercoutter, 1945, 344), a los escarabeos de pasta de importación egipcia a partir del siglo V. Uno de los centros de fabricación de escarabeos de jaspe, de gran importancia, es Cerdeña, origen que atribuye a los escarabeos de jaspe hallados en Cartago. Los escarabeos de jaspe verde con motivos egiptizantes se encuadran, según Vercoutter, en los siglos V y IV a. C., y su fabricación se debe a artesanos fenicios o púnicos sardos, ya que a partir del siglo IV a. C. son los escarabeos con temas griegos los más abundantes, hechos por artesanos griegos.

Así pues, y pese a que no hemos hallado ningún paralelo iconográfico en Cerdeña, puede que sea éste el punto de origen del escarabeo de La Alcudia, como indicaba Padró (Padró, 1983), siendo tomados como modelo para su fabricación los escarabeos de pasta de los siglos VII y VI a. C. provenientes de Egipto con representaciones del dios Ptah, como los hallados en Cartago. Así pues, una datación posible para este escarabeo sería la de los s. V-IV a. C., proporcionada por el material de fabricación y el estilo de la pieza, pese a que no exista, como hemos indicado, ningún paralelo iconográfico en jaspe verde.

\section{Marina Escolano Poveda \\ Estudiante de $3^{\circ}$ de Historia \\ Facultad de Filosofía y Letras \\ Universidad de Alicante \\ marina.seshat@wanadoo.es}

\section{BIBLIOGRAFÍA}

ACQUARO, E., 1977: Amuleti egiziani ed egittizzanti del Museo Nazionale di Cagliari, Roma.

ACQUARO, E., 1984: Arte e cultura punica in Sardegna, Roma.

ALLEN, J. P., 2000: Middle Egyptian. An Introduction to the Language and Culture of Hieroglyphs, Cambridge.

BLÁZQUEZ, J. Ma , 1970-1971: "Escarabeos de Ibiza", Zephyrus, Salamanca.

BLÁZQUEZ, J. Ma', 2000: "Los fenicios, transmisores de la cultura egipcia a Occidente", Los pueblos de España y el mediterráneo en la antigüedad. Estudios de arqueología, historia y arte, Madrid.
CASTEL, E., 1999: Egipto. Signos y símbolos de lo sagrado, Madrid.

CASTEL, E., 2001: Gran Diccionario de Mitología Egipcia, Madrid.

CINTAS, P., 1970: Manuel d'Archéologie Punique, París.

ERMAN, A. y GRAPOW, H., 1971: Wörterbuch der Aegyptischen Sprache, Berlín, $2^{\mathrm{a}}$ ed.

FAULKNER, R. O., 1988: A Concise Dictionary of Middle Egyptian, Oxford.

FEGHALI, A., 1996: Egyptian and Egyptianizing Scarabs. A typology of steatite, faience and paste scarabs from Punic and other Mediterranean sites, Oxford.

FERNÁNDEZ, J. H. y PADRÓ, J. 1982: Escarabeos del Museo Arqueológico de Ibiza, Madrid.

GAMER-WALLERT, I., 1978: Ägyptische und ägyptisierende Funde von der Iberischen Halbinsel, Wiesbaden.

GARDINER, A., 1957: Egyptian Grammar. Being an introduction to the study of hieroglyphs, Oxford, $3^{\mathrm{a}} \mathrm{ed}$.

GRIMAL, N., 1996: Historia del Antiguo Egipto, Madrid.

HALL, H. R., 1913: Catalogue of Egyptian Scarabs, etc., in the British Museum, Volume I: Royal Scarabs.

HORNUNG, E., 1976: Skarabäen und andere Siegelamulette aus Basler Sammlungen, Maguncia.

LANGE, K., 1961: Pirámides, esfinges, faraones, Barcelona.

MAGNARINI, F., 2004: Catalogo ragionato di una collezione di Scarabei-Sigillo Egizi, Oxford.

MORATALLA, J., 2004-2005: "La Alcudia ibérica: Una necesaria reflexión arqueológica", Lvcentvm, XXIII-XXIV, Alicante.

NEWBERRY, P. E., 1905: Ancient Egyptian Scarabs. An introduction to Egyptian seals and signet rings, Londres.

NEWBERRY, P. E., 1907: Scarab-Shaped Seals, Londres.

PADRÓ, J., 1980: Egyptian-type documents from the Mediterranean littoral of the Iberian Peninsula before the roman conquest. I. Introductory survey, Leiden.

PADRÓ, J., 1983: Egyptian-type documents from the Mediterranean littoral of the Iberian Peninsula before the roman conquest. II. Study of the material, Leiden.

PADRÓ, J., 1996: Historia del Egipto faraónico, Madrid.

PETRIE, W. M. F., 1917: Scarabs and cylinders with names, Londres.

RAMOS FERNÁNDEZ, R., 1974: De Heliké a Illici, Alicante.

RAMOS FOLQUÉS, A., 1950: "La Alcudia de Elche, antes y durante la dominación púnica", Crónica del I Congreso Nacional de Arqueología y del V Congreso Arqueológico del Sudeste. Almería 1949, Cartagena.

RAMOS FOLQUÉS, A., 1955: "Vestigios cartagineses en La Alcudia de Elche", Actas del I Congreso Arqueológico del Marruecos Español. Tetuán 1953, Tetuán.

SCANDONE, G. M., 1975: Scarabei e scaraboidi egiziani ed egittizzanti del museo nazionale di Cagliari, Roma.

TEETER, E. 2003: Scarabs, scaraboids, seals, and seal impressions from Medinet Habu, Chicago.

VERCOUTTER, J., 1945: Les objets égyptiens et égyptisants du mobilier funéraire carthaginois, París.

WILKINSON, R. H., 2003: Todos los dioses del Antiguo Egipto, Madrid. 